\title{
Heavy Oil Production System Optimisation using Electrical Submersible Progressive Cavity Pumps (ESPCP) in the Niger Delta
}

\author{
Remmy Chindu Eluagu, Stanley Toochukwu Ekwueme*, Ubanozie Julian Obibuike \\ Department of Petroleum Engineering, Federal University of Technology, Owerri (FUTO), Owerri, Nigeria
}

Email address:

stanleyekwueme@yahoo.com (S. T. Ekwueme)

${ }^{*}$ Corresponding author

\section{To cite this article:}

Remmy Chindu Eluagu, Stanley Toochukwu Ekwueme, Ubanozie Julian Obibuike. Heavy Oil Production System Optimisation using Electrical Submersible Progressive Cavity Pumps (ESPCP) in the Niger Delta. International Journal of Oil, Gas and Coal Engineering. Vol. 8, No. 2, 2020, pp. 40-46. doi: 10.11648/j.ogce.20200802.12

Received: February 5, 2020; Accepted: February 19, 2020; Published: April 17, 2020

\begin{abstract}
There is a growing interest which has accelerated efforts towards heavy oil production in recent years. This interest was stimulated by the rapidly exhausting conventional oil reserves which promises to leave the world, unless something is done, in less supply and scarcity of the world's most dominant energy source. Unlike conventional light oil, heavy oil possesses inherent challenges in its exploitation. Additionally, this challenge is more evident in crude oil flow either from the reservoir or from the well. Due to high viscosity, heavy oil production requires special non-conventional technologies designed for this purpose. Much efforts have been put by researchers and manufactures of oil technologies in the area of drilling, completion, production and enhanced oil recoveries. Artificial lift methods provide suitable means of lifting crudes from wellbore to the surface when primary reservoir energy is insufficient to do so. The Niger Delta field has been dominated by gas lift activities before now majorly because the oil is light with high GOR making gas available for injection which is a major factor favouring the choice of gas lift. But the recent shift to gas project development makes gas availability more competitive and this may threaten the predominance of gas lift. Furthermore, the new interest in heavy oil field development requires that new artificial lift system be designed for Niger Delta heavy oil application as gas lift is not applicable to heavy oil fluid characteristics. In this paper, a new artificial lift pump is proposed for use. The pump is a hybrid of Electric submersible and progressive cavity pump possessing the best capabilities of the two, it is called electric submersible progressive cavity pump and has been tested to possess potentials for lifting heavy crudes.
\end{abstract}

Keywords: ESPCP, Heavy Oilfield, Production Enhancement, Artificial Lift

\section{Introduction}

Heavy crude oil is a highly viscous oil that easily cannot flow to production wells or to the surface under primary reservoir drive energy. It is referred to as "heavy" because its density or specific gravity is higher than that of light oil. Heavy crudes have higher viscosities, higher specific gravities and heavier molecular composition than light oil [1].

Nigeria's conventional light oil is rapidly exhausting due to production and newer pools are not frequently discovered, thus, Nigeria may soon run out of oil production. This will affect the country drastically because its economy is heavily oil-dependent. In order to address this issue, Nigeria government must begin the development its vast heavy oil reserves to supplement production [1].

Recently, heavy oil have gained a lot of interest. Operators seek technical and economically viable means to recover viscous petroleum reserves. Despite the challenge, advancements in drilling, enhanced oil recovery methods and efficient production methods have made it possible.

Because of the complexities and cost associated with heavy oil production, profit making is usually a very critical factor in the choiced method of exploitation. Profit can be realized by using methods such as high efficiency extraction systems that allow reduction in energy consumption, 
production increase, and diminished operating cost resulting from equipment failures and extended operating life of equipment used for the extraction [2].

Artificial lift mechanisms are mostly used in conjunction with EOR processes in improving oil recovery from the reservoir to the surface $[3,4]$. This is majorly the case in heavy oil exploitation. Artificial lift utilizes some means to increase the flow of fluids (usually liquids like crude oil or water with some amount of gas included) to the surface of a production well. This is usually accomplished by a mechanical device inside the well, such as a pump; which decreases the weight of the liquid/gas mixture via high pressure gas or improving the lift efficiency of the well via velocity strings. An artificial lift system is needed in wells with insufficient pressure in the reservoir to boost the liquid to the surface. Additionally, these systems are often used in flowing wells to increase the naturally occurring flow rate [5].

When there is enough gas for injection either from an associated or non-associated gas reservoirs with a surface compression plant installed, gas lift may be considered as it offers one of the most versatile process used to artificially lift oil from wells where there is insufficient reservoir pressures to produce the well. However gas lift may be threatened by the increased utilization of gas for other applications due to the emergence of gas monetisation technologies. Furthermore, gas lift will not be practicable in lifting heavy crudes $[6,7]$.

Owing to the limitations of gas lift in handling heavy oils, other artificial lift methods such as use of artificial lift pumps may be considered in the design of heavy oil exploitation technologies. Among these pumps, progressive cavity and electric submersible pumps have increased tendencies for deployment. ESPs can be used in areas where heavy crudes limits the applicability of gas injection, or high water cut and low bottomhole pressures hinder the use of gas lift. PCPs provide many benefits in oilfield applications, such as high solid content tolerance, high viscosity fluids, horizontal and deviated wells and their simple installation and operation gives it additional benefits. However temperature and abrasion limits the use of PCPs especially in thermal production wells.

Some wellbore conditions limit the applicability of typical centrifugal or rod pumps, in such cases it may be necessary to design a new pump possessing hybrid qualities [9]. This hybrid technology possesses the best qualities of parent technologies and are more enhanced in performance having wider range of applicability. Electric submersible progressive cavity pumps have been designed by engineers to incorporate the best features of ESPs and PCPs. This paper analyses the potentials of using ESPCP in production of heavy oils in the Niger Delta.

\section{Artificial Lift Method Review}

We review artificial lift methods as means of lifting crude from the wellbore to the surface when primary recovery energy is no longer sufficient to do so. Also, emphasis is made on the artificial lift methods in the Niger Delta and the technologies that would be most suited to recover heavy crudes as Nigeria considers exploiting its heavy oilfields.

\subsection{Gas Lift in the Niger Delta}

Gas lift entails the injection of high-pressure gas from the surface into the producing fluid column through one or more subsurface valves set at predetermined depths. Injected gas aerates the fluid to reduce its density; the formation pressure is then able to lift the oil column and forces the fluid out of the wellbore. There are basically two types of gas lift methods used in the oil industry; these are Continuous-Flow Gas Lift and Intermittent Gas Lift [9].

The predominance of gas lift for lifting crudes from wellbore to the surface in the Niger Delta is due to the following reasons

1. The Niger delta oil has high GOR because of this it is usually considered as foamy crude.

2. The prevalence of conventional light oil exploitation

3. The availability of gas in high volumes for injection purposes

4. The immaturity of gas projects to compete with gas lift for natural gas

But certain develops will limit the use of gas lift in the Niger Delta. The emergence of gas utilization and monetisation technologies will increase the demand for available gas and thus lower the chances of getting 'cheap gas' for artificial lift injection. The new interest in exploiting heavy oils further limits the use of gas lift because of the high viscosity of heavy crudes.

\subsection{Artificial Lift Pumps as Parent Technology}

Artificial lift pumps are downhole pump used to increase the pressure in the well to overcome the sum of flowing pressure losses. Downhole pumps are used to increase pressure at the bottom of the tubing string by an amount sufficient to lift fluid to the surface. Artificial lift pumps includes sucker rod pumps, hydraulic pump, plunger lift, progressive cavity pumps (PCP) and electric submersible pumps [10]. PCPs are mainly used because of their high solids handling and viscous oil handling capacities. ESPs are especially effective in wells with low bottomhole pressure, low gas/oil ratio, low bubble point, high water cut or low API gravity fluids. ESPs mostly require constant and high power supply [7]. Some reservoir and well conditions are so complex that one artificial lift system may not possess all the desire capacity suitable for optimal recovery of the crudes to the surface. In such situation, it may be necessary to find ways to merge the capabilities of two or more technologies into one technology called a hybrid. Electric submersible progressive cavity pumps have emerged as a hybrid of ESP and PCP for lifting crudes of varied reservoir and well conditions. This technology has shown good potentials for applicability in lifting heavy crude from the wellbore to the surface [11]. 


\subsection{Electrical Submersible Progressive Cavity Pump, ESPCP}

In the petroleum industry, there are varieties of wellbore conditions that limit the use of typical centrifugal or rod pumps. For example, in wells with high gas content, fluids with high sand content, the performance of ESP is greatly reduced. In deviated wells mechanical wear occurs between the sucker rod pump and the production tubing. These create great problems during production. To solve these problems there is need to design hybrid technologies equipped with the useful features of the parent technologies. For example, Engineers designed Electric submersible progressive cavity pumps to solve the inherent problems of individual uses of electric submersible pump and progressive cavity pumps. This technology was developed to incorporate ESP motors with PCPs to create a new hybrid system. With this combination, PCPs are now able to match ESPs in depth and deviation capabilities [12].

The ESPCP system has the following components: the submersible motor, gear-reduction unit, seal section, flexshaft assembly, pump, variable speed drive and submersible cable.

1. Submersible Motor

ESPCP system has ESP motors, ranging from 10-hp to 2,000-hp. These motors are equipped with characteristics to maximize run life in harsh downhole conditions.

2. Gear-Reduction Unit (GRU)

GRU provides a high torque required to overcome interference fit between the rotor and the stator. This is major requirement of PCPs. The GRU is designed to alternate between speed and torque enabling easy working of the motor [8]. Standard electrical motors rotate at approximately 3,600-rpm at $60-\mathrm{Hz}$, higher than $\mathrm{PCP}^{\mathrm{s}}$ operating range which is typically 100 - to 500-rpm [8].

3. Seal Section

The seal section provides a shields the GRU and the motor from the presence of well fluids, equalizes the motor oil to the wellbore fluid pressure and supports the pump shaft thrust load.

\section{Flex-Shaft Assembly}

PCPs move in an eccentric motion while the motor, GRU and seal move in a concentric motion. Thus, it is necessary that eccentric motion be transferred to the concentric motion while dampening the vibration it causes. A flex-shaft assembly couples the seal shaft and the pump rotor to compensate for the eccentric rotation and vibration.

5. Pump

ESPCP pumps are the PCPs. PCPs are most effective in viscous oil, sand laden fluids and gassy wells. They are also more suitable when handling emulsions. Another benefit is that PCPs require smaller motors than ESPs, lowering energy costs.

6. Variable Speed Drives

This provide means to control the downhole ESPCP system. Being able to alter the settings on the downhole system allows operators to adjust production output as downhole conditions change [8]. The VSD protects the pumping system by sensing changing conditions such as flow or pressure that could potentially cause damage. Alarms and limits can be programmed in the VSD, allowing for automatic step changes to optimize production and operating conditions [8]. Variable speed drives also includes a graphical control system (GCS), this is a software with features designed to maximize the life of the pumping system. The GCS interface also records, logs and communicates data from the drive and any downhole monitoring system to a laptop, SCADA or satellite system [8].

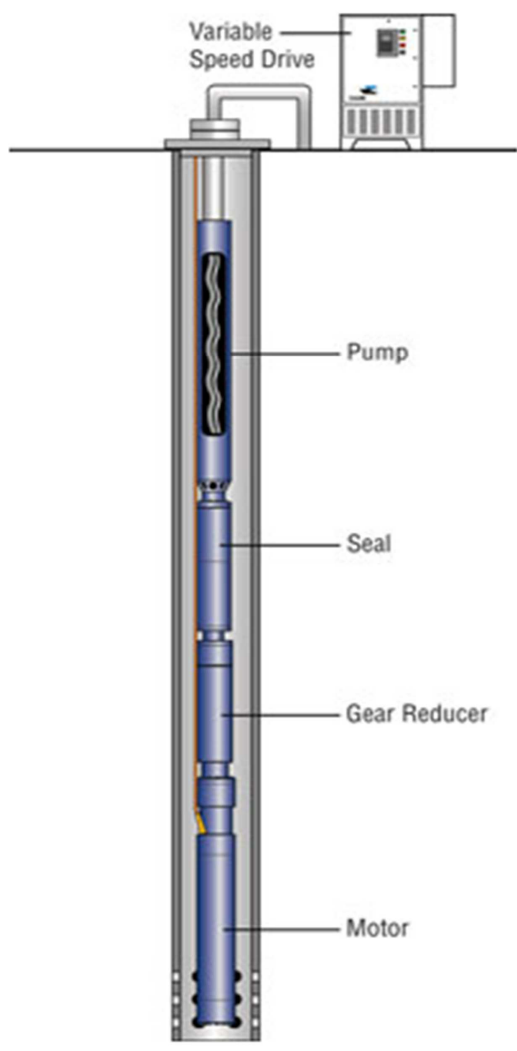

Figure 1. ESPCP system assembly [8].

\subsection{ESPCP Production and Deployments}

In U.S.A., ESPCP is mainly produced by Reda and Baker Hughes Centrilift Company. ESPCP technology has been successfully applied to the directional and horizontal wells, which makes up the defect of sucker rod pump and play a unique advantage in heavy oil recovery field. Centrilift Company manufactures all the key parts of ESPCP system including special armoured cable oil application design and variable speed motor controller. In Canada, Corod Company produces a variety of driving form and a variety of specifications of the ESPCP system.

In China, much applications of ESPCPs were in China National Offshore Oil Company (CNOOC), where about 140 ESPCPs are now used in the past years [13]. Also, in China, ESPCP was applied on Kulin Horizontal wells in 2003 and it resulted to higher pump efficiency compared to tubing pump efficiency. ESPCP 
offered longer pump run life, proven at Kulin Horizontal wells never had pump problems or pulling out job [14].

ESPCP deployment in 2014 in in Casebe field yielded great results. It was applied to three wells. Well 1 showed an outstanding performance (i.e. 12 times the historical run life). Well 2 and well 3 also increased run life by $704 \%$ and $635 \%$ respectively [15].

\section{Methods}

The well reservoir data is gotten $\mathrm{X}$-field in the Niger Delta. X-field is a heavy oil field of high viscosity, low API gravity and underlying weak aquifer. The reservoir history and unfavorable properties makes the reservoir to be unsuitable to be put to production by primary and secondary recovery methods. Thus EOR means by steam injection was applied to the reservoir to produce the fluids. The fluid continued to flow to the production interval and to the surface. After sometime, some wells showed difficulties in lifting the crudes to the surface as most crudes accumulated in the wellbore. It is intended that artificial lift pumps be applied in getting these fluids to the surface. ESPCP was chosen for application because of its uniqueness in viscous fluid handling. The performance of ESPCP were compared with that of gas lift for this production system.

Table 1. Reservoir, well, fluid and production data.

\begin{tabular}{ll}
\hline PVT Data & Values and their Units \\
\hline Initial Reservoir pressure & $3118 \mathrm{psia}$ \\
Formation volume factor at Reservoir pressure & $1.0686 \mathrm{rb} / \mathrm{stb}$ \\
Formation volume factor at Bubble point pressure & $1.0785 \mathrm{rb} / \mathrm{stb}$ \\
Fluid density & $56.11 \mathrm{lb} / \mathrm{ft} 3$ \\
Water density & $62.4 \mathrm{lb} / \mathrm{ft} 3$ \\
Gas density & $0.269 \mathrm{lb} / \mathrm{ft} 3$ \\
Viscosity of crude & $14.225 \mathrm{cP}$ \\
Reservoir Temperature & $136^{\circ} \mathrm{F}$ \\
Well radius, inch & $4\left(3 \frac{1}{2}\right), 7(23 / 8), 2(27 / 8)$ \\
No of wells & 13 \\
Tubing size on well & $4\left(3 \frac{1}{2}\right), 7(23 / 8), 2(27 / 8)$ \\
\hline
\end{tabular}

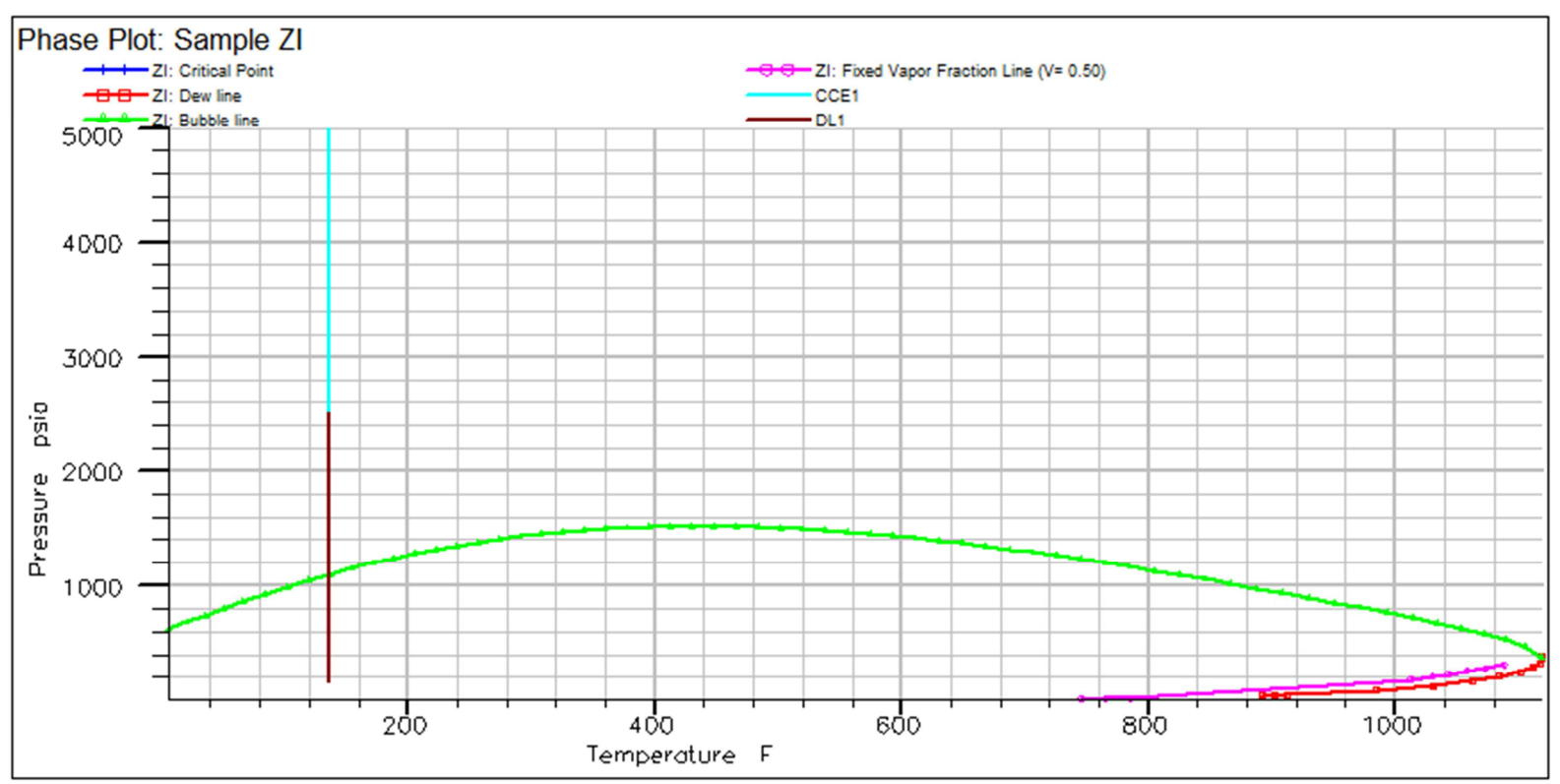

Figure 2. Phase plot after fluid experiment addition (CCE and DL).

Table 2. Petrophysical data.

\begin{tabular}{ll}
\hline Petrophysical Data & Values And Their Units \\
\hline Porosity & 0.28 \\
Permeability & $600-800 \mathrm{mD}$ \\
Wellbore ID & $1 \mathrm{ft}$ \\
Drainage radius & $100 \mathrm{ft}$ \\
Compressibility factor & $5.07 \mathrm{E}-6 \mathrm{psi}^{-1}$ \\
Reservoir depth & $7466 \mathrm{ft}$ \\
\hline
\end{tabular}

The phase diagram of the fluid model is shown in figure 2 above. Phase diagram is a pressure and temperature 
relationship that explains changes in a given fluid sample with varying temperature and pressure. The phase diagram does not account for the changes in composition at a given pressure and temperature. Therefore, phase diagram operates at constant fluid composition

Economic Evaluation

Before making a final decision on which method of artificial lift to be used, a thorough economic analysis needs to be carried out. It is the profitability of a project that has to be the final decision criteria. This study is still in the evaluation phase, and a full economic analysis giving the NPV of the projects is not available yet. The NPV will give the value of a project through its entire lifetime taking capital costs, operating costs, revenues into account. However, the initial costs of the scenarios are analyzed and can give a good indication of the project magnitude.

Table 3. Cost of artificial lift systems [6, 7]

\begin{tabular}{lll}
\hline Item & Gas Lift & ESPCP \\
\hline Target Rate (bbl/day) & 1000 & 1000 \\
Initial Installation (\$) & 120000 & 105000 \\
Energy Efficiency (\%) & 15 & 48 \\
Intake Pressure (psia) & 900 & 900 \\
Lift Energy (kw/bbl/day) & 0.1 & 0.031 \\
Workover Cost (\$/day) & 1000 & 1000 \\
\hline
\end{tabular}

Table 4. Cost on daily basis of artificial lift systems.

\begin{tabular}{llll}
\hline & Gas Lift & ESPCP \\
\hline DESCRIPTION & Daily cost & Annual cost & Daily cost \\
\hline Equipment (US\$) & 250000 & 250000 & 280000 \\
Installation (US\$) & 105000 & 105000 & 100000 \\
Horsepower (US\$/D) & 2303 & 840505 & 2533 \\
Running cost US\$/D & 8219 & 3000000 & 8219 \\
Maintenance Cost (US\$/D) & 1461 & 533333 & 1461 \\
Water treatment cost (US\$/D) & 959 & 350000 & 924648 \\
OPEX (US\$/D) & 12942 & 4723839 & 3000000 \\
CAPEX (US\$) & 355000 & 355000 & 3333 \\
\hline
\end{tabular}

\section{Results and Discussions}

The results of the economic evaluation of the analysis conducted for Gas Lift and ESPCP are given and discussed below

\subsection{Oil Rate}

The oil rate corresponds to the average daily production from each well for each year. The well production was considered for 20 years period from 1991 to 2010. Analysis were made for natural flow without any artificial lift method, and artificial lift with the use of Gas lift and ESPCP. Performance evaluation and economic analysis were then performed to ascertain the oil recovery and the economic indicators respectively for the two artificial lift methods used. An oil price of $\$ 60 / \mathrm{bbl}$ was used for the analyses. After the water has been separated from the total fluid rate, the resulting volume rate is the oil rate. The oil rate signifies that ESPCP pump gave higher recoveries than gas lift for the methods considered.

Table 5. Oil rate (bbl/day).

\begin{tabular}{|c|c|c|c|c|c|c|c|}
\hline Year & GOR, scf/stb & Water-Cut & Pressure (Psi) & Natural Flow, bbl & Gas Lift, bbl & ESPCP, bbl & Incremental Flowrate, bbl \\
\hline 1995 & 820 & 50 & 4246 & 3795 & 8497 & 9656 & 1159 \\
\hline 1996 & 820 & 55 & 4045 & 3286 & 7101 & 8069 & 968 \\
\hline 1997 & 820 & 57 & 3906 & 3031 & 6017 & 6838 & 821 \\
\hline 1998 & 820 & 59 & 3878 & 2792 & 5120 & 5818 & 698 \\
\hline 1999 & 820 & 61 & 3678 & 2508 & 4502 & 5116 & 614 \\
\hline 2000 & 820 & 62 & 3608 & 2259 & 4056 & 4609 & 553 \\
\hline 2001 & 820 & 63 & 3451 & 2126 & 3745 & 4255 & 510 \\
\hline 2002 & 820 & 65 & 3316 & 1901 & 3390 & 3852 & 462 \\
\hline 2003 & 820 & 66 & 3181 & 1739 & 3102 & 3536 & 434 \\
\hline 2004 & 820 & 67 & 3046 & 1583 & 2864 & 3255 & 391 \\
\hline 2005 & 820 & 69 & 2911 & 1389 & 2538 & 2884 & 346 \\
\hline 2006 & 820 & 70 & 2776 & 1250 & 2308 & 2622 & 314 \\
\hline 2007 & 820 & 72 & 2641 & 1078 & 2016 & 2291 & 275 \\
\hline 2008 & 820 & 72 & 2506 & 989 & 1878 & 2134 & 256 \\
\hline 2009 & 820 & 73 & 2371 & 868 & 1677 & 1906 & 229 \\
\hline 2010 & 820 & 73 & 2236 & 783 & 1544 & 1755 & 211 \\
\hline 2011 & 820 & 74 & 2101 & 672 & 1358 & 1544 & 186 \\
\hline 2012 & 820 & 74 & 1966 & 590 & 1230 & 1398 & 168 \\
\hline 2013 & 820 & 74 & 1831 & 507 & 1102 & 1252 & 150 \\
\hline
\end{tabular}




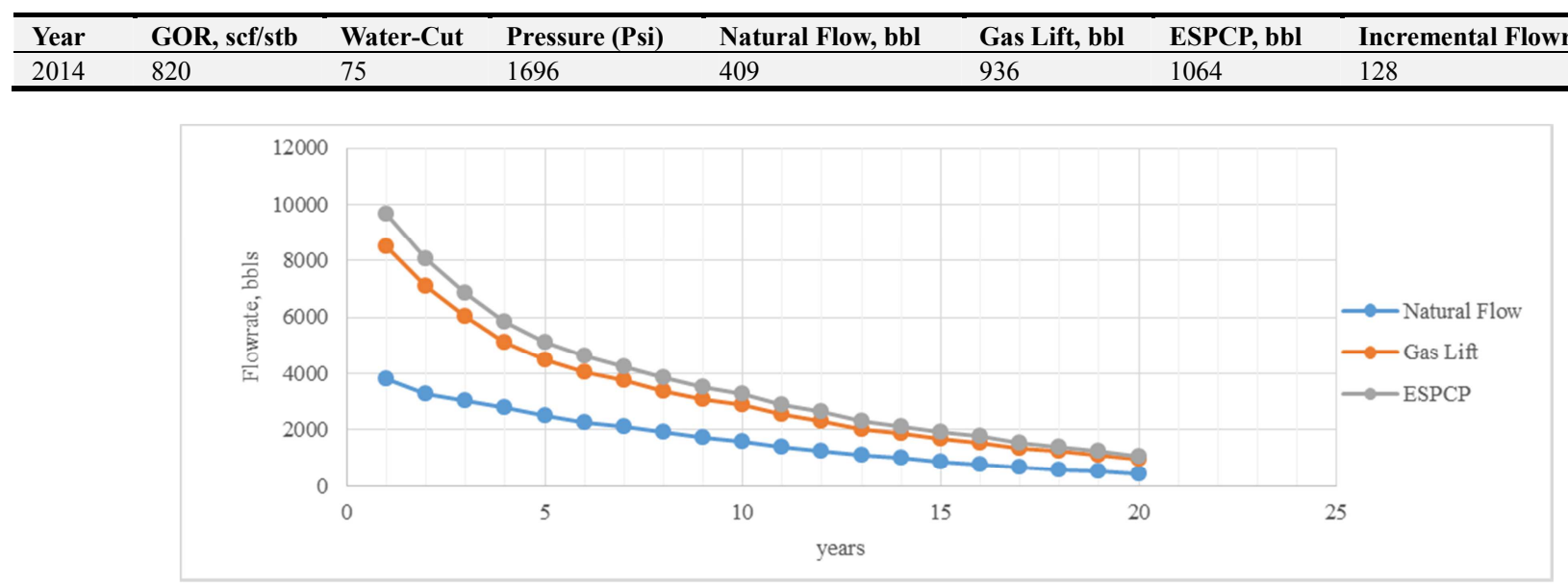

Figure 3. Oil rates for artificial lift pumps and natural flow.

From figure 3 above, it can be observed that ESPCP gives higher fluid recoveries from the same wells than gas lift.

\subsection{Economic Indicators}

The economic indicators calculated from the deployment of ESPCP instead of gas lift is given in table 6 below.

Table 6. Summary of Economic Parametres for the Artificial Lift Systems.

\begin{tabular}{lll}
\hline Economic Parameter & ESP & ESPCP \\
\hline NPV (US\$) & 787716320 & 41106240 \\
Incremental Cashflow (US\$) & 746610080 & \\
Pay Out (Yrs) & 1 & 1 \\
DCF-ROR (\%) & 120 & 105 \\
\hline
\end{tabular}

\section{Conclusions}

Two artificial lift methods have been evaluated: gas lift and ESPCP pump. It is seen from the analysis that ESPCP show greater adaptability to be deployed in the Niger Delta heavy oilfield than gas lift. The economic analysis reveal that ESPCP is economically more feasible to be used for artificial in lifting heavy crude than gas lift. A 20 year period is taken for the analyses. The economic analyses shows a higher NPV for ESPCP than gas lift. Also, the discounted cashflow rate of return (DCFROR) for ESPCP is greater than that for gas lift is making ESPCP preferable gas lift for this operation.

Therefore, ESPCP is recommended for use in the Niger Delta owing to its viscous crude handling capability. This will save the gas used for injection in gas lift which can be monetized for additional revenue.

\section{References}

[1] Ossai, P. G. O, Ohia, P. N, Obah, B, Duru, U. I, Onaiwu, D. O (2017). Enhanced Recovery of Heavy Oil in the Niger Delta: Nelson and McNeil model a key option for in-situ combustion application. Advances in Petroleum Exploration and Development. (14) 2, 27-33.

[2] Pothapragada, V., Al Kooheji, H., Al Hajri, S., and Siyabi, I. (2012). "Integrated Production System Modeling of the
Bahrain Field", Society of Petroleum Engineers 155596, SPE International Production and Operations Conference \& Exhibition, Doha, Qatar.

[3] Jorge Doval. (2017). "Implementation of ESPCP Technology to Decrease Well Intervention Index in Casabe Field," Paper: SPE 187215-MS, presented at the SPE Annual Technical Conference \& Exhibition, San Antonio, TX, USA.

[4] Wang, H., Wang, S., and Lv, X. (2016). "The effects of temperature on the mechanical and tribological properties of progressing cavity pump NBR stator rubber," Mechanika, vol. 22 , no. 4 , pp. $308-312$.

[5] Mehrdad Alemi, Hossen Jalalifar, Gholamreza Kamali and Mansour Kalbasi: (2010) "A prediction to the best artificial lift method selection on the basis of TOPSIS model", Journal of Petroleum and Gas Engineering Vol. 1 (1), pp 009-015.

[6] Chikwere Ezekiel, Okotie Sylvester, Dulu Appah. (2015). "Economic Evaluation of Electrical Submersible Pump (ESP) and Gas Lift Well for Production Optimization in a Niger Delta Field," International Journal of Engineering and Technology, January series. Vol. 5 No. 1.

[7] Aliyev Elshan (2013). Development Of Expert System For Artificial Lift Selection, Master's Thesis Submitted to the Department of Petroleum and Natural Gas Engineering, Graduate School of Natural and Applied Sciences of Middle East Technical University.

[8] Shirley Kathy. (2011). Electrical Submersible Progressing Cavity Pump Systems. Baker Hughes, Centrilift.

[9] Halliburton, (2008). "Basic Artificial Lift", Canadian Oil Well Systems Company Ltd. pp. 2-8

[10] Osakwe, L. O. (2015). "Artificial lift systems - design and operations," Institute of Petroleum Studies, PPD 610-2 Lecture Note.

[11] Patron, K. E., Villarreal, P. M., Villalobos Leon, J. L., Schlumberger. (2017). "Case Studies of Optimizing the Artificial Lift Strategy for Reactivating Abandoned Wells in a Mature Field," Paper: SPE 187363-MS, presented at the SPE Annual Technical Conference \& Exhibition, San Antonio, TX.

[12] Kefford, P. A., Gaurav, M. (2016) "Well Performance Calculations for Artificial Lift Screening," Paper: SPE 181344-MS, presented at the SPE Annual Technical Conference \& Exhibition, Dubai, UAE. 26-28 September. 
[13] Feng Bao, Weibin Meng, Anxia Li, Xiaocheng Zang, Liangchuan Li, Bingchnag Wu, Xin Li. (2010). "The Application of ESPCP in China Oilfield," Paper: SPE 136816, presented at the SPE Progressive Cavity Pumps Conference, Edmonton, Alberta, Canada. 12-14 September.

[14] Taufan, M., Adriansyah, R. and Satriana, D. (2005). "Electrical Submersible Progressive Cavity Pump (ESPCP) Application in Kulin Horizontal Wells,” Paper: SPE 93594-
MS, presented at the Asia Pacific Oil \& Gas Conference and Exhibition, Jakarta, Indonesia. 5 - 7 April

[15] Cristhian C., Tello Bahamon, Carlos Reyes Hill, Carlos Sanita, Ricardo Artola, Femando Lapania, Jorge Doval. (2017). "Implementation of ESPCP Technology to Decrease Well Intervention Index in Casabe Field," Paper: SPE 187215MS, presented at the SPE Annual Technical Conference \& Exhibition, San Antonio, TX, USA. 9-11 October. 